polarisation, and examination between crossed Nicols failed to elicit any appearance indicating strains in the glass. The spectra seemed to be identical with the colours of thin plates, with which they agree in being much brighter in reflected than in transmitted light. The colours are also complementary in the two cases, as can easily be shown by the use of a micrometer eyepiece; the colour of the band lying on a certain division being noted, the moving of a suitably arranged screen cuts off the light from the mirror under the stage and allows that from a condensing lens above the stage to fall on the glass; the

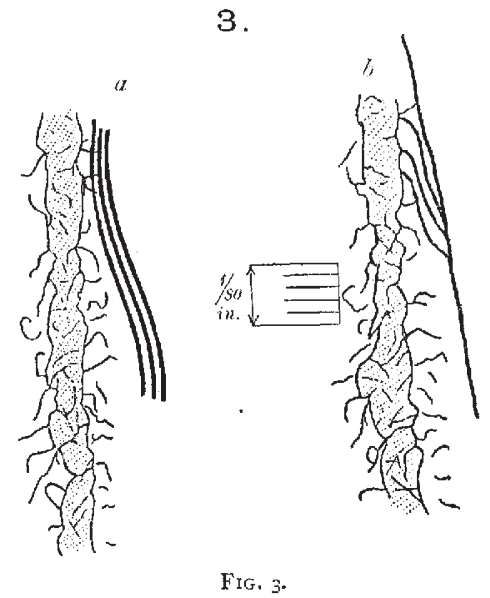

colour is then seen to change into its complementary, passing through white if the two lights are of suitable relative brightness. If the surface layers of the glass near the scratch are separated somewhat from those below, the interval forms a thin plate, and this would suffice to account for the spectra, as the separation would necessarily reach a maximum at the scratch, and we there find the spectra nearest together; moreover, along the edge of the outermost spectrum, the black of the first order is quite distinct wherever the spectra are broad enough to allow their colours to be distinguished. The splitting perpendicularly to the cleavage plane would then be quite analogous to that seen in other brittle

4.

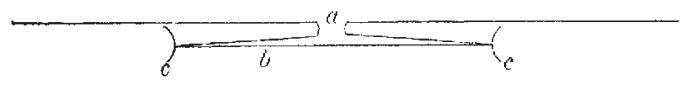
$\begin{aligned} \text { Fig. } 4 \cdot-a=\text { the scratch } ; b=\text { the cleft under the torn-up surface layer } ; c c & =\text { the splits. }\end{aligned}$

substances, and as every one must have repeatedly observed it in cutting such substances as camphor, paraffin, or ice (Fig. 4 shows the condition of the glass on this supposition). That a tendency really exists in scratched glass for the surface layers to tear up we know from the fact that splinters of glass near the scratch will often keep peeling off for days together.

$$
\text { E. F. J. LOVE, }
$$

Demonstrator of Physics in the Mason College

Birmingham, July I4

Prof. Sylvester's Articie on "A New Example of the Use of the Infinite and Imaginary in the Service of the Finite and Real"

I sHoulv like to be allowed to mention that Mr. Buchheim has drawn my attention to the fact that one of the theorems in the postscript to my recent article in NATURE contained in the formula -

$$
P^{\prime}: Q^{\prime}=\frac{P: Q}{\sqrt{P: P} \sqrt{Q: Q}}
$$

is virtually given under a slightly different notation in the second edition of Grassmann's "A usdehnungslehre," p. I4I.

July 12

\section{Rainfall of N.W. England}

THE rainfall on the coast-line of the Dee and the sea from Chester to Llandudno in the spring and summer months presents some interesting features. $\Lambda \mathrm{s}$ a rule the amount of rain is the greatest at the Chester end in the spring months (April to June), and at the Llandudno end in the summer months (July to September). This is shown by the following table:-

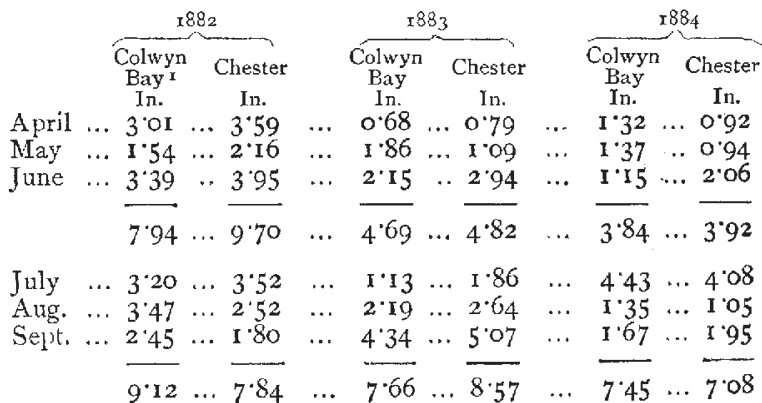

That this result is not a mere coincidence will be gathered from the following statement of the rainfall last month (June, I885) at Chester, Colwyn Bay, and Bagillt, this last being between the other two places, at a distance of fifteen miles from the former

\begin{tabular}{|c|c|c|c|c|c|c|}
\hline & & Chester & & Bagrillt & & Colwyn Bas \\
\hline June & & In. & & In. & & In. \\
\hline 5 & $\cdots$ & 0.12 & $\cdots$ & 0.07 & $\ldots$ & 0.18 \\
\hline 6 & $\cdots$ & 38 & $\cdots$ & $2 \mathrm{I}$ & $\cdots$ & 20 \\
\hline 7 & $\cdots$ & 33 & $\cdots$ & 29 & $\ldots$ & -24 \\
\hline 8 & $\ldots$ & II & $\cdots$ & .05 & $\ldots$ & OI \\
\hline 16 & $\ldots$ & 18 & $\ldots$ & $\cdot 15$ & $\ldots$ & .03 \\
\hline I8 & $\ldots$ & ·10 & .. & .06 & $\ldots$ & .05 \\
\hline I9 & $\cdots$ & 04 & $\cdots$ & .02 & $\ldots$ & 02 \\
\hline 20 & $\ldots$ & •16 & $\ldots$ & .09 & $\cdots$ & ${ }^{\circ} 3$ \\
\hline 23 & $\ldots$ & 79 & ... & 46 & ... & 32 \\
\hline 24 & $\ldots$ & I 3 & ... & .08 & $\ldots$ & 02 \\
\hline 29 & $\cdots$ & - & $\ldots$ & ${ }^{\circ} \mathrm{O} 2$ & $\cdots$ & 一 \\
\hline & & $2 \cdot 34$ & $\ldots$ & I'50 & $\ldots$ & I. IO \\
\hline
\end{tabular}
or twenty-five miles from the latter :-

It will be seen that on every day, except one, the rainfall was highest at Chester, Bagillt coming next, and Colwin Bay being the lowest. There must therefore be some definite law which governs this gradual decrease from east to west; and in the hope of drawing out the opinions of more skillful meteorologists on the subject, I venture to suggest the following explanation.

It is generally admitted that atmospheric currents travelling across the Atlantic from the south-west reach our islands charged with aqueous vapour almost to saturation. These, meeting the mountains of Wales and Cumberland, are driven up into a higher and colder region where the moisture is condensed into rain, causing a very heavy rainfall on the zeestern slopes. Now if a line be drawn south-west from Colwin Bay, it will be found to pass over some of the highest mountains in Wales, so that in spring, when the air above these mountains is still cold, the moisture is so effectually condensed that there is little left to fall on the north-east side. But if a parallel line be drawn south-west from Chester it passes over no very high region, and the moisture is therefore less completely drained from the atmosphere. But, as the summer goes on, the mountain-tops become warmer and the condensation on them less complete, and then more rain is left to fall on the north-east side, $i e$, at Colwyn Bay. And as the summer day temperature is higher at Chester. than Colwyn Bay, less rain is condenscd at the former place.

Chester, July is ALFRED O. WALKER

\section{"Foul Water"}

My attention has just been called to Mr. Shrubsole's letter under above title. Having been for several weeks past engaged in dredging off the North Wales coast, I have continuously noticed the profuse amount of gelatinous bodies diffused throughout the sea, evidently of the same character as observed by Mr. Shrubsole off Shecrness. 'They appcared here early in June.

The little bodies are distinctly visible on holding a bottle of sea-water up to the light. They vary in size from $1 / \mathbf{r} 6$ th to

$$
{ }^{x} \text { Colwyn Bay is about five miles east of Llandudno. }
$$

